\title{
Contralateral pneumothorax after central line placement in COVID-19 positive patients
}

\author{
Elizabeth Swezey, Scott Oster, Kathryn McGhee, Luke Edgecombe, Jody C. DiGiacomo, L.D. George Angus \\ Department of Surgery, Nassau University Medical Center, East Meadow, NY, USA
}

\section{Mini-Abstract}

Three patients, intubated due to COVID-19, were identified with a new pneumothorax after central venous catheter placement, but on the opposite side. These pneumothoraces were not the consequence of the line placement procedure, but coincidental due to the pulmonary pathology of the COVID-19 virus.

\begin{abstract}
Contralateral pneumothorax after percutaneous central venous catheter placement has not been previously reported. Three patients who required intubation and mechanical ventilation for
\end{abstract}

Correspondence: Jody C. DiGiacomo, M.D., FACS, Department of Surgery, Nassau University Medical Center, 2201 Hempstead Turnpike, East Meadow, NY 11554, USA.

E-mail: jdigiac1@numc.edu

Key words: COVID-19; pneumothorax; central line.

Contributions: ES, SO, conception and design; data collection and analysis; manuscript writing and approval of final version; KMG, LE, conception and design; data collection and analysis; manuscript writing, critical analysis and revision, approval of final version; JCD, LDGA, conception and design; data analysis; manuscript critical analysis and revision, approval of final version. All the authors have read and approved the final version of the manuscript and agreed to be accountable for all aspects of the work.

Conflict of interest: The authors declare that they have no competing interests, and all authors confirm accuracy.

Ethics approval: This project received approval of the Nassau University Institutional Review Board.

Received for publication: 22 June 2021.

Accepted for publication: 13 August 2021.

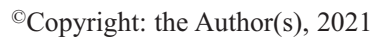

Licensee PAGEPress, Italy

Monaldi Archives for Chest Disease 2022; 92:1986

doi: 10.4081/monaldi.2021.1986

This article is distributed under the terms of the Creative Commons Attribution Noncommercial License (by-nc 4.0) which permits any noncommercial use, distribution, and reproduction in any medium, provided the original author(s) and source are credited. acute respiratory failure due to COVID-19 were identified with a new pneumothorax on routine post-placement chest roentgenogram on the side opposite the catheter placement. Retrospective review of charts, radiographs, and laboratory studies. No causative relationship was identified between the percutaneous placement of the central venous catheters and the subsequent pneumothoraces identified on the contralateral side, other than the presence of active COVID-19 viral pneumonia. The timing of the contralateral pneumothoraces were coincidental the placement of the central venous catheters. We believe these pneumothoraces were a consequence of the pulmonary pathology of the COVID-19 virus.

\section{Introduction}

The most common cause of iatrogenic pneumothorax is central venous catheterization, which comprises $43.8 \%$ of cases [1], especially when placed in the subclavian vein [2]. Thoracentesis was noted as the second most common cause (20.1\%), and barotrauma secondary to mechanical ventilation was the third $(9.1 \%)$ [1]. All reported cases of pneumothorax found in the literature were ipsilateral to the central line placed.

The authors report three cases of contralateral pneumothorax after central line placement in patients infected with the novel COVID-19 virus. These patients were all tested for COVID-19 with a reverse transcriptase polymerase-chain-reaction (RT-PCR) nasopharyngeal swab, and all received COVID-19 therapy which included intubation/sedation/paralytics, daily manual proning as tolerated, antibiotics to prevent bacterial superinfection, hydroxychloroquine, and steroids as clinically indicated to combat the cytokine storm. Inflammatory markers, including fibrinogen, ferritin, c-reactive protein, d-dimer, and lactate dehydrogenase were sent to monitor the severity of the cytokine storm. These patients represent a previously unreported clinical presentation of the COVID-19 infection and the cytokine storm.

\section{Case \#1}

A 47-year-old non-smoking male with a past medical history (PMH) of diabetes was admitted with an $\mathrm{O}_{2}$ saturation (sat) of $99 \%$ on room air (RA), fever, cough, and shortness of breath (SOB) due to COVID-19 pneumonia. He required intubation on hospital day (HD) 10. Initial ventilatory settings were: assist control, rate of 35 breaths per min, tidal volume $\left(\mathrm{V}_{\mathrm{T}}\right)$ of 400 milliliters $(\mathrm{mL})$, a positive end expiratory pressure (PEEP) of 13, and a fraction of inspired oxygen $\left(\mathrm{F}_{\mathrm{i}} \mathrm{O}_{2}\right)$ of $100 \%$. His peak airway pressure 
was 35. The highest PEEP from HD 0 to HD 18 was 16 , and the highest peak airway pressure was 60 . On hospital day 18 , under ultrasound guidance, a right internal jugular (IJ) central line was placed in one attempt. Pre-procedure chest X-ray (CXR) did not show a pneumothorax (Figure 1A). At the time of placement, the PEEP was 14, the $\mathrm{V}_{\mathrm{T}}$ was $400 \mathrm{~mL}$, and the peak airway pressure was 42. Post-procedure CXR four hours later showed an appropriate right $\mathrm{IJ}$ and a new left pneumothorax (Figure 1B). As the patient was hemodynamically stable, it was observed with serial CXRs, and resolved on hospital day 20. He died on hospital day 28. Subsequent CXRs documented no pneumothorax recurrence. His COVID-19 inflammatory marker trend is detailed in Table 1, though no markers of inflammation were obtained before the pneumothorax occurred.

\section{Case \#2}

A 58-year-old non-smoking female with a PMH of obesity and hypertension was admitted with an $\mathrm{O}_{2}$ sat of $97 \%$ on RA, dry cough, nausea, vomiting and diarrhea due to COVID-19 pneumonia. She required intubation on HD 9. Initial ventilatory settings were: assist control, rate of 28 breaths per minute, $\mathrm{V}_{\mathrm{T}}$ of $380 \mathrm{~mL}$, $\mathrm{FiO}_{2}$ of $100 \%$, and a PEEP of 15 . Her peak airway pressure was 29 . The highest PEEP from HD 0 to HD 20 was 20, and the highest peak airway pressure was 48 . On HD 20, a right peripherally inserted central catheter (PICC) line was placed in one attempt under ultrasound guidance. At the time of PICC placement, the PEEP was 20, the $\mathrm{V}_{\mathrm{T}}$ was $400 \mathrm{~mL}$, and the peak airway pressure

Table 1. COVID-19 inflammatory marker trend.

\begin{tabular}{|c|c|c|c|c|}
\hline $\begin{array}{l}\text { Patient } 1 \\
\text { Marker }\end{array}$ & Normal values & HD 1-17 & HD $18 *$ & HD 20 \\
\hline Fibrinogen (mg/dL) & $188-459$ & & 655 & 776 \\
\hline D-Dimer (ug/mL) FEU & $<0.4$ & - & 19.06 & 17.34 \\
\hline C-reactive protein (mg/dL) & $0.0-0.9$ & - & 18.1 & 36.1 \\
\hline Lactate dehydrogenase (U/) & $120-246$ & & 351 & 433 \\
\hline Ferritin $(\mathrm{ng} / \mathrm{mL})$ & $10.5-307.3$ & - & 1071.6 & 1607.6 \\
\hline $\begin{array}{l}\text { Patient } 2 \\
\text { Marker }\end{array}$ & Normal Values & HD 18 & HD 20* & HD 23 \\
\hline Fibrinogen (mg/dL) & $188-459$ & 917 & & 475 \\
\hline D-Dimer (ug/mL) FEU & $<0.4$ & 9.22 & - & 8.4 \\
\hline C-reactive protein (mg/dL) & $0.0-0.9$ & 31.7 & - & 6.4 \\
\hline Lactate dehydrogenase (U/) & $120-246$ & 609 & & 563 \\
\hline Ferritin $(\mathrm{ng} / \mathrm{mL})$ & $10.5-307.3$ & 730.6 & & \\
\hline $\begin{array}{l}\text { Patient } 3 \\
\text { Marker }\end{array}$ & Normal Values & HD 10 & HD $16^{*}$ & HD 27 \\
\hline Fibrinogen (mg/dL) & $188-459$ & & & \\
\hline D-Dimer (ug/mL) FEU & $<0.4$ & 2.91 & - & 5.4 \\
\hline C-reactive protein (mg/dL) & $0.0-0.9$ & 15.3 & - & 7.7 \\
\hline Lactate dehydrogenase (U/) & $120-246$ & 408 & & 814 \\
\hline Ferritin $(\mathrm{ng} / \mathrm{mL})$ & $10.5-307.3$ & 1559.2 & & 2654.7 \\
\hline
\end{tabular}

$\mathrm{HD}$, hospital day; ${ }^{*}$ day of pneumothorax.
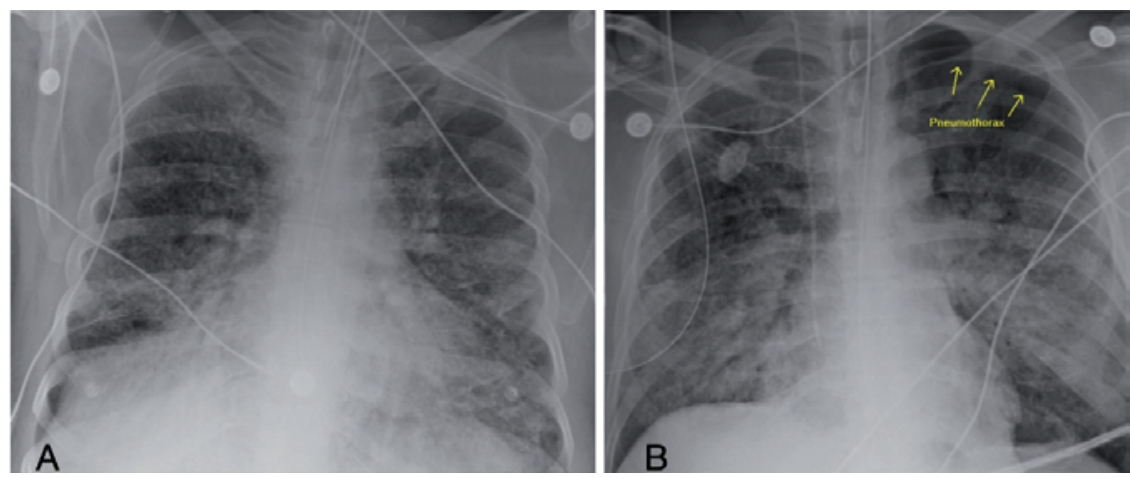

Figure 1. Patient \#1 pre- and post- central line placement $\mathrm{X}$-rays A) Pre-procedure $\mathrm{X}$ ray: no pneumothorax. B) Post-procedure $\mathrm{X}$-ray: left pneumothorax identified. 
was 34. Post-procedure chest x-ray showed appropriate positioning of right PICC (Figure 2A). The following day's CXR revealed the PICC had migrated into the right ventricle (Figure 2B), and the PICC was withdrawn to an appropriate position. The patient desaturated, with saturations reaching the 50's, and became hemodynamically unstable. Repeat CXR showed a large left pneumotho$\operatorname{rax}$ (Figure 2C). An emergent chest tube was placed. This patient was eventually discharged to subacute rehab on HD 84. Her COVID-19 inflammatory marker trend is detailed in Table 1.

\section{Case \#3}

A 29-year-old non-smoking male was admitted with an $\mathrm{O}_{2}$ sat of $94 \%$ on RA, cough, fever, fatigue, and SOB due to COVID-19 pneumonia. He required intubation on HD 4. Initial ventilatory settings were: assist control, rate of 14 breaths per minute, $\mathrm{V}_{\mathrm{T}}$ of 380 $\mathrm{mL}, \mathrm{FiO}_{2}$ of $100 \%$, and a PEEP of 8 . The highest PEEP from HD 0 to HD 16 was 18 , and the highest peak airway pressure was 57 . On HD 16, a right subclavian central line was placed in one attempt. Pre-procedure CXR did not show a pneumothorax (Figure $3 \mathrm{~A}$ ). At the time of central line placement, PEEP was $15, \mathrm{~V}_{\mathrm{T}}$ was $450 \mathrm{~mL}$, and peak airway pressure was 29. Post-procedure CXR performed two hours later showed appropriate placement of the right subclavian central line and a moderate left sided pneumotho$\operatorname{rax}$ (Figure 3B). A chest tube was placed. This patient was eventually discharged home on HD 64. His COVID-19 inflammatory marker trend is detailed in Table 1.

\section{Discussion}

Unilateral ipsilateral iatrogenic pneumothorax is a well-recognized complication of central line placement. There have even been reports of bilateral pneumothoraces after central line placement, due to the presence of congenital interpleural communications [3]. There is no evidence for the presence of inter pleural communication in our patients. After a detailed literature search, we were unable to identify any instances of contralateral pneumothorax after central line placement, or even any cases at all of pneumothorax after PICC line placement in the literature.

All three of these patients did have multiple risk factors for pneumothorax. They were all on mechanical ventilation, in the presence of underlying lung disease, at high PEEPs. As mentioned previously, barotrauma is the third most common cause of iatrogenic pneumothorax [2]. Anzueto et al. reports the rate of barotrauma in mechanically ventilated patients at $2.9 \%$ [4]. Peak airway pressures over $50 \mathrm{~cm} \mathrm{H}_{2} \mathrm{O}$ are associated with increased risk of alveolar rupture [5], and when plateau pressures are maintained at less than $35 \mathrm{~cm} \mathrm{H}_{2} 0$, studies have shown that there is no relationship between ventilatory parameters and pneumothorax [6]. All three of our patients had peak airways pressures less than 50 when the central lines were placed, though they did rise above 50 prior to central line placement and pneumothorax in patient 1 and 3 . Plateau pressures were not recorded. While high tidal volumes are also risk factor for barotrauma [7], all three of our patients were being managed as acute respiratory distress syndrome patients, and were being ventilated with low tidal volumes, at $6 \mathrm{~mL} / \mathrm{kg}$.
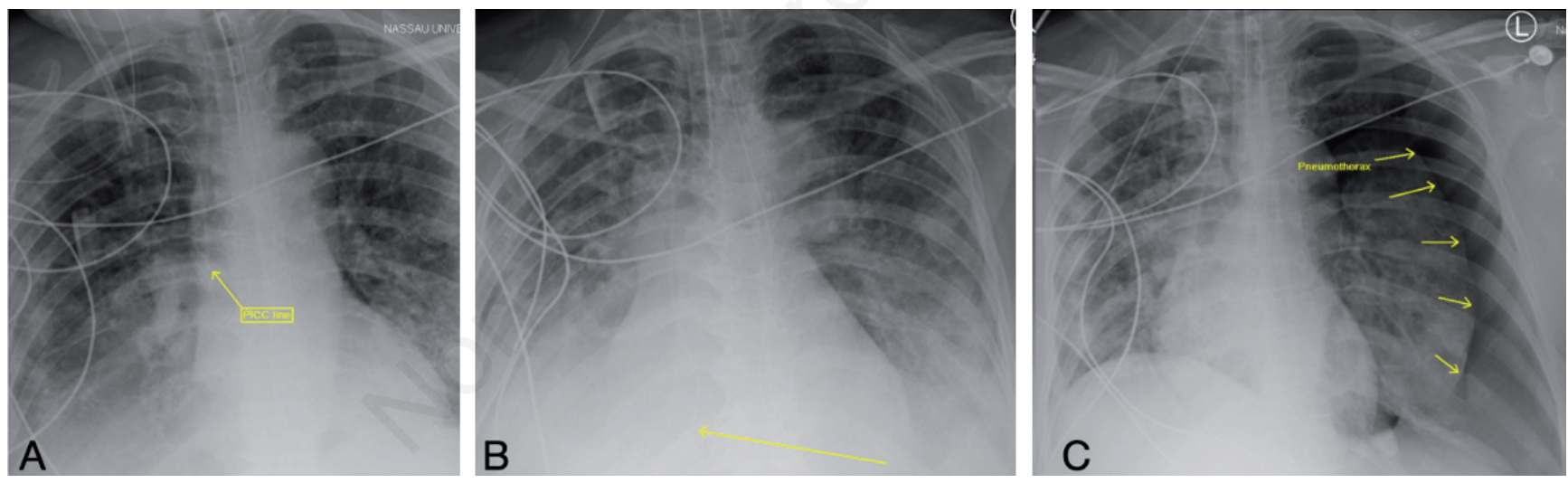

Figure 2. Patient \#2 X-rays of pneumothorax development. A) Post-procedure X-ray: appropriately placed PICC line, no pneumothorax. B) Migration of R PICC line into the right ventricle. C) Large left pneumothorax with adjusted PICC line placement.
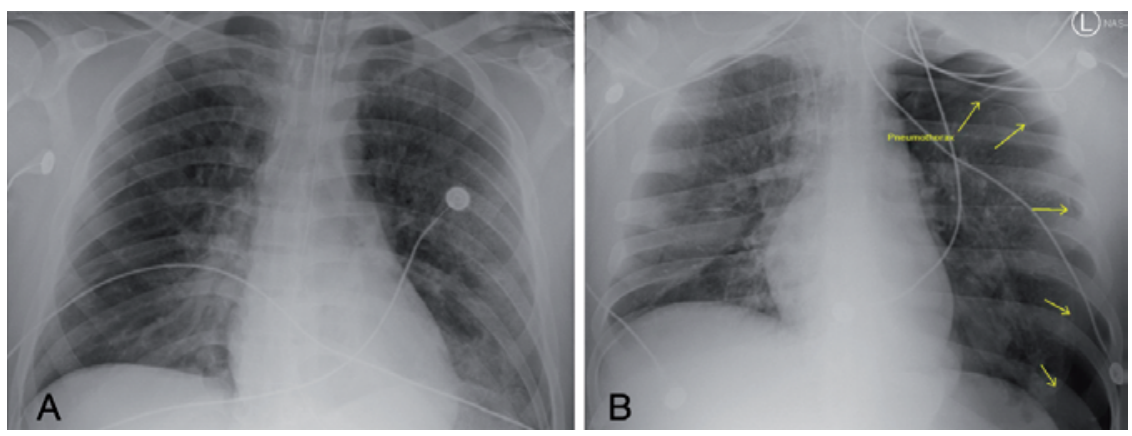

Figure 3. Patient \#3 pre- and post- central line placement $x$-rays. A) Pre-procedure Xray: no pneumothorax. $B$ ) Post-procedure $X$ ray: moderate left pneumothorax identified. 
All patients in this case series were infected with the SARSCoV-2. On autopsy, respiratory findings of COVID-19 patients include edema, proteinaceous exudate, focal reactive hyperplasia of pneumocystis with patchy inflammatory cellular infiltration, and multinucleate giant cells [8]. The virus infects alveolar epithelial cells via angiotensin converting enzyme II, damages the epithelium and activates immune cells, sets off an acute inflammatory cytokine storm, and can eventually lead to multi-organ dysfunction, including the cardiovascular and pulmonary systems [9]. For all three of our patients, inflammatory markers associated with the COVID-19 cytokine storm were sent at various time points all five inflammatory markers were significantly elevated at time of central line placement. We believe the damage to the lung parenchyma and the friability of the lung tissue from the cytokine storm were the major contribution to these pneumothoraces which would have been considered spontaneous or due to barotrauma were they not temporally coincidental to the central line placement. As such, they are an anecdote for how severe the effects of COVID-19 are on the pulmonary system. COVID-19 has a broad range of clinical presentations, and the exact effects of this inflammatory response are still being fully elucidated. Extensive research is warranted on how COVID-19 and the cytokine storm leads to contralateral pneumothorax during central line placement in some patients, but clinicians should be vigilant not only for pneumothoraces bilaterally during central line insertion in patients with COVID-19, but also keep a high level of suspicion for pneumothoraces in COVID-19 patients without other risk factors for pneumothorax.

\section{Conclusions}

The identification of the contralateral pneumothoraces in these three patients were coincidental the placement of the central venous catheters, and were not iatrogenic. We believe these pneumothoraces were a consequence of the pulmonary pathology of the COVID-19 virus.

\section{References}

1. Celik B, Sahin E, Nadir A, Kaptanoglu M. Iatrogenic pneumothorax: Etiology, incidence and risk factors. Thorac Cardiovasc Surg 2009;57:286-90.

2. Tsotsolis N, Tsirgogianni K, Kioumis I, et al. Pneumothorax as a complication of central venous catheter insertion. Ann Transl Med 2015;3:40.

3. Pazos F, Masterson K, Inan C, et al. Bilateral pneumothoraces following central venous cannulation. Case Rep Med 2009;2009:745713.

4. Anzueto A, Frutos-Vivar F, Esteban A, et al. Incidence, risk factors, and outcomes of barotrauma in mechanically ventilated patients. Intensive Care Med 2004;30:612-9.

5. Hsu CW, Sun SF. Iatrogenic pneumothorax related to mechanical ventilation. World J Crit Care Med 2014;3:8-14.

6. Boussarsar M, Thierry G, Jaber S, et al. Relationship between ventilatory settings and barotrauma in the acute respiratory distress syndrome. Intensive Care Med 2002;28:406-13.

7. Ioannidis G, Lazaridis G, Baka S, et al. Barotrauma and pneumothorax. J Thorac Dis 2015;7:S38-S43.

8. Tian S, Weidong H, Niu L, et al. Pulmonary pathology of earlyphase 2019 novel coronavirus (COVID-19) pneumonia in two patients with lung cancer. J Thorac Oncol 2020;15:700-4.

9. Geng YJ, Wei ZY, Qian HY, et al. Pathophysiological characteristics and therapeutic approaches for pulmonary injury and cardiovascular complications of coronavirus disease 2019. Cardiovasc Pathol 2020;47:107228. 